\title{
Faculty and Student Attitudes about Transfer of Learning
}

\author{
Robin Lightner, PhD \\ Associate Professor of Psychology, Department of Behavioral Science \\ Raymond Walters College, University of Cincinnati \\ Ruth Benander, PhD \\ Professor of English, Department of English and Communication \\ Raymond Walters College, University of Cincinnati
}

\author{
Eugene F. Kramer \\ Associate Professor of Math, Department of Math, Physics, and Computer Science \\ Raymond Walters College, University of Cincinnati
}

Transfer of learning is using previous knowledge in novel contexts. While this is a basic assumption of the educational process, students may not always perceive all the options for using what they have learned in different, novel situations. Within the framework of transfer of learning, this study outlines an attitudinal survey

concerning faculty and student attitudes about transfer of learning. Faculty and students completed a measure of expectations for transfer and potential barriers to transfer. The survey clarifies unique and common beliefs about transfer in order to promote learning beyond a single course. The results show a clear need for faculty to be explicit about their expectations for transfer.

Sometimes the simplest questions are the most important ones to ask, and they often result in simple answers that are ironically difficult to implement. Basic questions like "Why don't students remember what we did last semester?" concern our most fundamental assumption about the function of teaching and the purpose of learning. Our educational system is based on this assumption that students transfer what they learn in one course to another, ultimately graduating with accumulated knowledge they can apply to their careers. The transfer of learning is an assumption that merits study. Mestre and his colleagues (2002) provide this definition: "We define transfer of learning (hereafter transfer) broadly to mean the ability to apply knowledge or procedures learned in one context to new contexts" (p. 3). Marini and

Sometimes the simplest questions are the most important ones to ask, and they often result in simple answers that are ironically difficult to implement.

Genereux (1995) define transfer of learning as

"prior knowledge affecting new learning or performance" (p. 2). An example of effective transfer would be when a student learns to create graphs in geometry and can then create graphs for a lab report in chemistry. An example of lack of transfer, where a teacher might expect transfer, would be when a student does not know how to do references for a history paper, although he or she may have done several papers with references in a previous composition course. To begin to break down this complex problem, this study examines and compares faculty and student attitudes about the transfer of learning.

Research into the process of transfer shows how problematic it is to assume that transfer happens automatically. In fact, it does not, and there are many barriers in traditional teaching that may actually inhibit such transfer, barriers such as assessments that emphasize recall of discrete facts rather than application in various contexts, lack of practice applying concepts to different situations, or lack of interdisciplinary references in lectures. The research into the transfer of learning has presented a complex picture. Relevant areas of study include the processes and awareness of transfer as well as the transfer of skills and concepts. In addition, researchers have examined transfer itself and instruction methods that promote transfer.

McKeough, Lupart and Marini (1995) present an excellent collection of 
papers outlining the facets of transfer in terms of different tasks, different learner variables, and different contexts. They suggest that, given the complexity of transfer, instructors should focus on teaching learners to generalize their knowledge so they can better transfer what they know from one situation to another. Transferring knowledge from one situation to a similar situation, or near transfer, seems to be relatively easy, while transferring knowledge to novel situations, or far transfer, seems more difficult (Bransford, Brown \& Cocking, 1999; Barnet \& Ceci, 2002). In fact, what a student considers near or far transfer can depend on his or her individual perceptions or expectations of what is similar or novel.

In terms of the transfer of specific skills, Salomon and Perkins (1987) suggest that it may be easier to transfer physical skills from one context to another, while transferring generalized concepts may be more difficult. They call the use of automatic skills in varied contexts "low-road transfer," such as knowing how to drive a car and then learning to drive a small truck. This type of transfer is accomplished through practice, and the depth of transfer greatly depends on the variation of the context during practice. "High-road transfer" is the conscious, formal abstraction of concepts in one situation which supports making connections to another type of situation, such as knowing how to use a clutch in a car and then learning how to use a clutch on a motorcycle. These outcomes of transfer are mediated by what learners believe they can know, and how well they can reflect on that knowledge.

Due to the many variables involved in transfer of learning, the body of research in the $20^{\text {th }}$ century has been wide-ranging. In an effort to better focus research on transfer, in 2002 the National Science Foundation (NSF) held a workshop on transfer of learning; the resulting report outlined a theoretical agenda for research

\section{Due to the many variables involved in transfer of learning, the body of research in the $20^{\text {th }}$ century has been wide-ranging.} about transfer of learning. This agenda included promotion of studies that explore teacher and learner beliefs and strategies that would promote transfer from one content area to another, as well as inquiry into the role of situated metacognition in transferring learning from one context to another. The participants in the workshop suggested that research should include not only laboratory-based studies but also real-world observations to better understand the learning and teaching strategies that best promoted transfer. The transfer of learning theories reviewed by this NSF workshop suggest a framework for examining metacognitive strategies and the application of knowledge. These theories translate readily into practice as classroom assessment techniques and interventions that promote metacognition, such as creating tests that assess broad transfer of concepts; helping learners appreciate the practicality of transferring ideas from one context to another; and helping teachers appreciate the value of letting students struggle with difficult material.

Whereas research has begun to examine instructional methods (e.g. Case \& Gunstone, 2002; DeCorte, 2003), metacognitive processes (Pressley et al., 2001), and self-regulation (Winne \& Hadwin, 1998; Zimmerman \& Kitsantas, 2002), little attention has been focused on the attitudinal components of transfer. Pea (1987) discussed how attitudes influence transfer of learning, but did not measure attitudes or offer data to support this idea. In his research, he suggested that learner beliefs about the appropriate context for a skill will strongly influence its transfer. He used the example of Brazilian street children who could do calculations when they were selling merchandise on the street, but who were unable to do basic math when they got to school (p. 644). This research suggests that attitudes about what can be learned and where it is appropriate to apply certain knowledge are culturally conditioned. The discussion concluded that teachers should focus on helping students become more metacognitively aware, so that they can use their knowledge more effectively for transfer. McCombs and Marzano (1990) also showed that attitudes are key to self-regulation models affecting metacognition. Before a student can be metacognitively aware, he or she must believe that this is possible and desirable.

InSight: A Journal of Scholarly Teaching 
Inferences about faculty expectations may contribute to these beliefs. Students may not spontaneously understand that faculty expect them to use information from previous classes without specific instruction. Anecdotally, students are more concerned about what a particular teacher wants on a given assignment. They actively try to adapt to these idiosyncratic requirements (Sherman, 1985). Thus, students may focus more on what they think the teacher wants, than on what kinds of thinking the assignment requires. Pressley et al. (1998) found that students are very aware of factors that guide studying style. What students see as idiosyncratic requirements may actually be expectations of more general transfer that they do not understand. For instance, formatting citations is a general skill that varies in style from one discipline to another. A psychology teacher may hope in vain that a student will transfer what she has learned about MLA source citations in her English course to her psychology course; while the English teacher may mistakenly think she has prepared a student for a history paper by teaching humanities citation format for an English composition research paper.

Clearly, the research indicates that while faculty expect transfer, there are many barriers to such transfer. The work done in attitudinal factors suggests that students' attitudes towards learning exert a powerful force on the strategies they choose to use. Thus, if we want to promote transfer of learning, students and faculty need to share an expectation of transfer as a foundation for promoting it. A group of faculty at our college created a faculty learning community to investigate why it is apparently difficult for students to transfer information they learned in past courses to present courses. We began our investigation with the basic assumption of faculty that transfer of learning is inherent to the learning process. We wanted to know if this was also the students' perceptions of transfer. To further

Students may not spontaneously understand that faculty expect them to use information from previous classes without specific instruction.

explore the relationship of student and faculty attitudes concerning transfer of learning, we surveyed students and faculty from the same institution to find out how similar their expectations of transfer and perceptions of the barriers to transfer might be. Both groups completed a survey about learning attitudes and provided examples of transfer. The researchers hypothesized that faculty's attitudes would include higher expectations for transfer than students', which may underlie faculty's perception that there are problems with transfer. Furthermore, the survey explored their attitudes about barriers to transfer to find out if students perceived barriers that faculty were not aware of.

\section{Method}

\section{Participants}

Participants included full- and part-time faculty members $(n=45)$ from a variety of disciplines at a two-year college and students $(n=265)$ from a variety of courses. This convenience sample of courses was likely to be representative of the college where the average age of students is 27 , and $60 \%$ of the students are female.

\section{Measures}

Participants rated items on Likert-type scales with responses from 1 (Strongly Disagree) to 5 (Strongly Agree) concerning, first, the importance of transfer; second, the ease of transferring material across similar contexts; and finally, across dissimilar contexts. Additionally, participants indicated their agreement on Likert-type scales from 1 (Strongly Disagree) to 5 (Strongly Agree) with statements about the impact of six potential barriers to transfer: a) relevance of the material; b) need to focus on what individual teachers want; c) knowing the 
material well enough; d) liking to think that hard; e) confusion; and f) time constraints. An open-ended question asked for other potential factors that would inhibit transfer, and students were asked to describe a project or assignment that required them to pull in material from another course.

\section{Results}

\section{Transfer Attitudes}

Table 1 shows that student and faculty attitudes concerning transfer differ considerably. Although students reported that course material overlaps somewhat between courses, and they sometimes think about that overlap, they believe that transfer is less important than faculty think, $t(306)=7.05, p=.01$. Faculty reported that to relate material from one course to the next is not as difficult as students believe, $t(306)=2.80, p=.01$. Students and faculty agreed that the carryover should be greater in the same subject than from one subject to another; but the faculty had higher expectations for transfer of learning within disciplines than the students, $t(306)=4.90, p<.01$, and across disciplines, $t(306)=4.19, p$ $=.00$.

Table 1: Means and Standard Deviations of Student and Faculty Ratings of Attitudes about Transfer

\begin{tabular}{|l|c|c|}
\hline & $\begin{array}{c}\text { Students } \\
(\mathrm{n}=264)\end{array}$ & $\begin{array}{c}\text { Faculty } \\
(\mathrm{n}=44)\end{array}$ \\
\hline The material applies/overlaps & $3.29(1.05)$ & -- \\
\hline $\begin{array}{l}\text { I often think about } \\
\text { other courses' material }\end{array}$ & $3.18(.80)$ & -- \\
\hline It is important to relate material & $3.59(.96)$ & $4.64(.61)$ \\
\hline It is easy to use or apply material & $3.27(.89)$ & $2.83(.93)$ \\
\hline Professors (I) expect carryover: Same subject & $3.87(.93)$ & $4.56(.59)$ \\
\hline Professors (I) expect carryover: Different subject & $3.07(.80)$ & $3.66(.75)$ \\
\hline $\begin{array}{l}\text { Note. Questions are on 5-point Likert scales from Never to Always or from Not at All } \\
\text { to Extremely. All differences are statistically significant, } p<.01 .\end{array}$ \\
\hline
\end{tabular}

\section{Barriers to Transfer}

Table 2 shows noteworthy differences between faculty and student attitudes about the factors that affect transfer. Faculty acknowledged more readily than students that the relevance of the material may inhibit transfer, $t(305)=$ $4.75, p=.01$. Students agreed more strongly than faculty that the student needs to focus on what the teacher wants, $t(306)=8.06, p=.01$. Faculty reported that poor command of the material inhibits transferring knowledge more than students did, $t(306)=3.94, p=.01$. When asked whether transfer would confuse a student, faculty and students both disagreed that this would be the case. However, the faculty reported that confusion hinders transfer less than the students indicated that it could, $t(305)=3.73, p=.01$. Faculty and students indicated that lack of time was not as important a barrier to transfer as other factors; but the students reported, more than faculty did, that being pressed for time can inhibit transfer, $t(305)=2.25, p=.03$. 
Table 2: Means and Standard Deviations of Student and Faculty Ratings of Factors Affecting Transfer

\begin{tabular}{|l|c|c|}
\hline & Students $(\mathrm{n}=264)$ & Faculty $(\mathrm{n}=44)$ \\
\hline The material is relevant & $3.68(.69)$ & $3.27(.76)$ \\
\hline $\begin{array}{l}\text { I (Students) need to focus } \\
\text { on what the teacher } \\
\text { wants }\end{array}$ & $4.20(.74)$ & $3.27(.97)$ \\
\hline $\begin{array}{l}\text { I (Students) don't know } \\
\text { the material well enough } \\
\text { yet }\end{array}$ & $2.66(.87)$ & $2.34(.91)$ \\
\hline $\begin{array}{l}\text { I (Students) don't like to } \\
\text { think that hard }\end{array}$ & $3.82(.84)$ & $1.95(1.05)$ \\
\hline It might confuse students & $2.57(1.00)$ & $2.45(1.04)$ \\
\hline $\begin{array}{l}\text { I (Students) don't have } \\
\text { time }\end{array}$ & $2.80(1.01)$ & \\
\hline $\begin{array}{l}\text { Note. Questions are on 5-point Likert scales from Strongly Disagree to Strongly } \\
\text { Agree. All differences between student and faculty ratings are significant, } p<.05 .\end{array}$ \\
\hline
\end{tabular}

In the open-ended responses, faculty mentioned the difficulty of creating explicit connections. Responses to the question "Are there any other factors that keep the material in one course separate from what's being taught in another course?" include the following:

- $\quad$ Faculty personal preference --unwillingness to negotiate.

- There is no coordination of material. Coordinating would improve uptake.

- $\quad$ Faculty not attempting to generate such responses and connections.

- Professors use different language to describe the same processes so it may be hard to recognize.

- $\quad$ Some professors are idiosyncratic about what they specifically require and thus build a silo around themselves.

- Lack of references to examples beyond the discipline and outside the classroom.

\section{Student Experiences with Transfer}

Although students rated transfer as less important than faculty did on the attitude survey questions, in the open-ended answers, students provided several examples of transfer. Some students readily cited making connections on their own with positive, confident results:

- "Well, I have had to write papers before that required remembrance of other courses. It is not so much that the professors require it, it just pops into my head so I am willing to use it. I might not know for sure about the facts I learned in another class, but it usually sounds at least familiar."

- "One example [of transfer] is History of Modern Europe- I previously took Art History beginning with the Renaissance. This same material began our Mod. Europe course-Humanism, rediscovering Ancient Rome and Greek culture. It was a nice advantage to know a bit about what happened then; we have to go to the Art Museum for Modern Europe Class and compare medieval art to Renaissance art. I am confident doing this assignment due to my Art History class."

- "Due to my understanding of certain classes, I find myself catching on quicker in others. Classes always, for some reason, coincide with one another causing my brain to be soothed by the familiarity of general (sometimes specific) ideas." 


\section{Discussion}

This attitudinal survey showed that overall, both faculty and students report that they have expectations about transfer. Students reported transfer of skills and concepts from one course to another, not just related courses in a series. However, faculty reported higher expectations for both near and far transfer situations. The difficulties students reported include lack of time and needing to meet the demands of a specific instructor.

Many students provided examples of transfer in open-ended questions in this study. They reported making spontaneous transfers that were not explicitly part of a given course. These results are encouraging. In contrast, some common classroom practices may not facilitate transfer. Alexander and Murphy (1999) suggest that learning environments are often specifically structured against the practice of transfer, including the instructor not modeling, rewarding, encouraging, or giving opportunities to express transfer. Alternatively, faculty might assume it is the student's responsibility to transfer knowledge, and leave it entirely up to the student to make the necessary connections. Therefore, students are left on their own to understand, for example, that their citation skills can be used in other courses or that their critical thinking skills will help them in any course. Engle (2006) found that when instructors framed multiple contexts for applying student learning among elementary school students, the students were able to explain phenomena better in different situations. This framing could be equally useful, in albeit more complex circumstances, at the college level; there, faculty could make more explicit interdisciplinary connections during instruction, or create assignments that involved students in a variety of applications of course content. When instructors explicitly design classroom assignments with transfer in mind, then transfer is more likely to happen.

However, students' beliefs that transfer should occur within and across disciplines still lag behind faculty views. It is possible that students do not always know that faculty expect transfer and thus do not report that they believe that it should happen. Also, students report in the survey what they perceive to be idiosyncratic faculty requirements as barriers to transfer. Thus, students might not believe faculty find transfer to be important. This survey shows a clear need for faculty to be explicit about their expectations for transfer. Assignments requiring reflection about prior learning can communicate transfer expectations, while reference to specific skills learned in other courses would indicate that expectations are not idiosyncratic.

Suggestions from these survey results,

This survey shows a clear need for faculty to be explicit about their expectations for transfer.

the transfer literature, and our experiences with transfer include rewarding the student who brings examples from other contexts into classroom discussions. For example, a biology instructor might ask students to include in presentations what current research is being done on the topic they have chosen to present. Also, encouraging and modeling transfer can help students understand that transfer is not only possible but useful. For example, history courses could include literary works from the time period under study, chemistry courses could include social implications of chemical technologies, or literature courses could include visual art representing the aesthetics of the literary period of study. In this way, teachers can ask students to generate possible applications or uses of the material in a forwardlooking practice (Halpern \& Hakel, 2003); or, teachers can include references to how other disciplines view or work with the concepts that are being discussed in a particular class. It may also be helpful to decontextualize information to get students to see the bigger picture and be able to recognize ideas in other settings (Salomon \& Perkins, 1989). For example, in a psychology course, students might be asked to think about how historians' work is affected by the hindsight bias, or in a math course, students could study how advances in mathematical thought have changed perceptions of the universe over time.

InSight: A Journal of Scholarly Teaching 
In response to student perceptions that idiosyncratic requirements block transfer, faculty might communicate better within and between departments on common skills they expect to transfer. For example, a college-wide discussion of citation expectations could help students receive a more consistent message about citation in papers. Natural sciences and mathematics faculty might discuss the common skills they expect students to command; they can then remind students that those skills are transferable and ensure that these skills appear at coordinated times in the larger program curriculum.

Student learning communities, problem-based learning, and inquiry learning can encourage transfer. The goal of transfer and its theoretical framework underlies these techniques. The goal of a university education is to promote students' knowledge to transfer beyond the college experience. The point is to promote in-class learning as

Student learning communities, problembased learning, and inquiry learning can encourage transfer.

significant to students' lives, beyond the "learn and dump" model of cramming for exams (e.g., Fink, 2003). This goal can be fostered by creating learning experiences where the connections between content areas can be explored in meaningful ways that require students to solve real-world problems by taking interdisciplinary approaches (e.g. Michelson, Knight, \& Fink, 2004).

There are other techniques that can encourage reflection which promotes transfer even in lecture classes. These reflective techniques include requiring elaboration, having multiple opportunities for retrieval, and practicing with a variety of examples. Other reflective techniques, such as Think-Pair-Share and minute papers, require students to stop passive note-taking and engage the material actively (Nilson, 2003). All of these active learning techniques affect the engagement and general understanding of the immediate subject matter, which encourages transfer. If a student is not engaged in the subject matter, the likelihood that he or she will retain the information is low. A student who cannot understand how information can be generalized has more difficulty reflecting on how it might be used in novel contexts. Active learning strategies encourage creative application of knowledge by changing attitudes about the variety of opportunities to use the material from class.

This attitudinal survey is a simple way to begin the exploration of transfer attitudes. This study did not look at whether attitudes predicted transfer; however, it can inform faculty of the need to address the transfer issue explicitly. Some limitations of the current survey study include the potential social desirability problem of a survey. Perhaps, instead of asking about interest in transfer, future studies could analyze actual course assignments across disciplines. This analysis could identify required elements of transfer as an indication of transfer expectations. Another issue is the fit of transfer within the curriculum. Many of the transfer theorists make teaching recommendations at the course level, but neglect to show how courses fit together in the larger curriculum. These larger curricular issues may be more predictive of transfer than individual techniques. In industry, researchers found that creating a culture of transfer mattered. Bates and Khasawneh (2005) found that organizations needed to actively create climates that encouraged transfer. In such a climate, employees were more likely to make innovative applications. Finally, many of the suggestions for improving transfer through active learning do not have data to support them; nor do we fully understand what factors in these techniques promote transfer. Future studies should examine the impact of these elaborative exercises, not just on the retention of the material, but on the ability to recognize opportunities to use the material in other contexts.

Transfer of learning is an important issue for faculty to consider. The assumption of transfer underlies the entire educational system-universities are predicated on the belief that students will be able to apply in their careers what they learned in the classroom. There is a folk-belief that contradicts this idea, expressed 
in the t-shirt philosophy, "I went to college and all I got was this piece of paper." This assumption, that there is no transfer of what a person learns in college, needs to be specifically addressed. Students can and should transfer knowledge from one course and discipline to another. This process is difficult, and faculty members should help students master it. Innovations in teaching should help students make connections with what they know.

\section{References}

Alexander, P. A. \& Murphy, P. K. (1999). Nurturing the seeds of transfer: A domain-specific perspective. International Journal of Educational Research, 31, 561-576.

Barnett, S. \& Ceci, S. (2002). When and where do we apply what we learn? A taxonomy for far transfer. Psychological Bulletin, 128(4), 612637.

Bates, R. \& Khasawneh, S. (2005). Organizational learning culture, learning transfer climate and perceived innovation in Jordanian organizations. International Journal of Training and Development, 9(2), 96-109.

Bransford, J., Brown, A., \& Cocking, R. (1999). How people learn: Brain, mind, experience, and school. Washington D.C.: National Academy Press.

Case, J. \& Gunstone, R. (2002). Metacognitive development as a shift in approach to learning: An in-depth study. Studies in Higher Education, $27,459-470$.

DeCorte, E. (2003). Transfer as the productive use of acquired knowledge, skills, and motivations. Current Directions in Psychological Science, 12(4), 142-146.

Engle, R. E. (2006). Framing interactions to foster generative learning: A situative explanation of transfer in a community of learners classroom. The Journal of the Learning Sciences, 15(4), 451-498.
Fink, D. (2003). Creating significant learning experiences: An integrated approach to designing college courses. Hoboken, NJ: Jossey Bass/Wiley.

Halpern, D. \& Hakel, M. (2003, August). Applying the science of learning. Change, 36-41.

Marini, A. and Genereux, R. (1995). In Teaching for Transfer: Fostering Generalization in Learning. (eds, McKeough, A., Lupart, J. and Marini, A.) Lawrence Erlbaum Associates, Mahwah, NJ, pp. 1-20.

McCombs, B. \& Marzano, R. J. (1990). Putting the self in selfregulated learning: The self as agent in integrating will and skill. Educational Psychologist, 25, 51-69.

McKeough, A., Lupart, J., \& Marini, A. (Eds.). (1995). Teaching for transfer: Fostering generalizations in learning. Mahwah, NJ: Erlbaum.

McNeese, M. D. (2000). Sociocognitive factors in the acquisition and transfer of knowledge. Cognition, Technology, and Work, 2, 164-177.

Mestre, J. (2002). Transfer of learning: Issues and research agenda. LSC Net. Retrieved September 10, 2003 from http://Iscnet.terc.edu/do.cfm/paper/11553/sh ow/use_set-library.

Michelson, L., Knight, A., \& Fink, D. (2004). Team based learning: $A$ transformative use of small groups in college teaching. Sterling, VA: Stylus Publishing. 
Nilson, L. (2003). Teaching at its best: A research-based resource for college instructors. Bolton, MA: Anker Publishing.

Pea, R. D. (1987). Socializing the knowledge transfer problem. International Journal of Educational Research, 11, 639-663.

Pressley, M., Van Etten, S., \& Freebern, G. (1998). The metacognition of college studentship: A grounded theory approach. In D. Hacker, J. Dunlosky, \& A. Graesser, (Eds.), Metacognition in educational theory and practice (pp. 347-66). New Jersey: LEA.
Salomon, G. \& Perkins, D. (1989). Rocky roads to transfer: Rethinking mechanisms of a neglected phenomenon. Educational Psychologist, 24(2), 113-142.

Sherman, T. M. (1985). Learning improvement programs: A review of controllable influences. The Journal of Higher Education, 56(1), 85-100.

Winne, P. \& Hadwin, A. (1998). Studying as self-regulated learning. In D. Hacker, J. Dunlosky, \& A. Graesser (Eds.), Metacognition in educational theory and practice (pp. 277-304). New Jersey: LEA.

Zimmerman, B. J. \& Kitsantas, A. (2002). Acquiring writing revision and self-regulatory skill through observation and emulation. Journal of Educational Psychology, 94, 660-668.

Robin Lightner received her doctorate in Psychology at the University of Kentucky and has been working at the University of Cincinnati since 2001. She is currently the co-director of the Raymond Walters College learning and teaching center. Dr. Lightner teaches Intro Psych, Social Psychology, and Personality Theories.

Ruth Benander received her doctorate from the University of Pennys/vania and has been teaching at the University of Cincinnati since 1996. She was the co-director of the Raymond Walters College learning and teaching center from 2000-2006. Dr. Benander teaches English Composition and Post-colonial literature at the undergraduate level.

Eugene Kramer has been a faculty member at the University of Cincinnati since 2000, and is currently pursuing his doctorate. He teaches Algebra and Calculus and has participated in a number of faculty learning communities. 